\title{
Salmonella typhimurium meningitis in an adult patient with AIDS
}

K Swe Swe, G Nagel, M Van der Westhuizen and A A Hoosen

J. Clin. Pathol. 2008;61;138-139; originally published online 8 Dec 2006; doi:10.1136/jcp.2006.043216

Updated information and services can be found at:

http://jcp.bmijournals.com/cgi/content/full/61/1/138

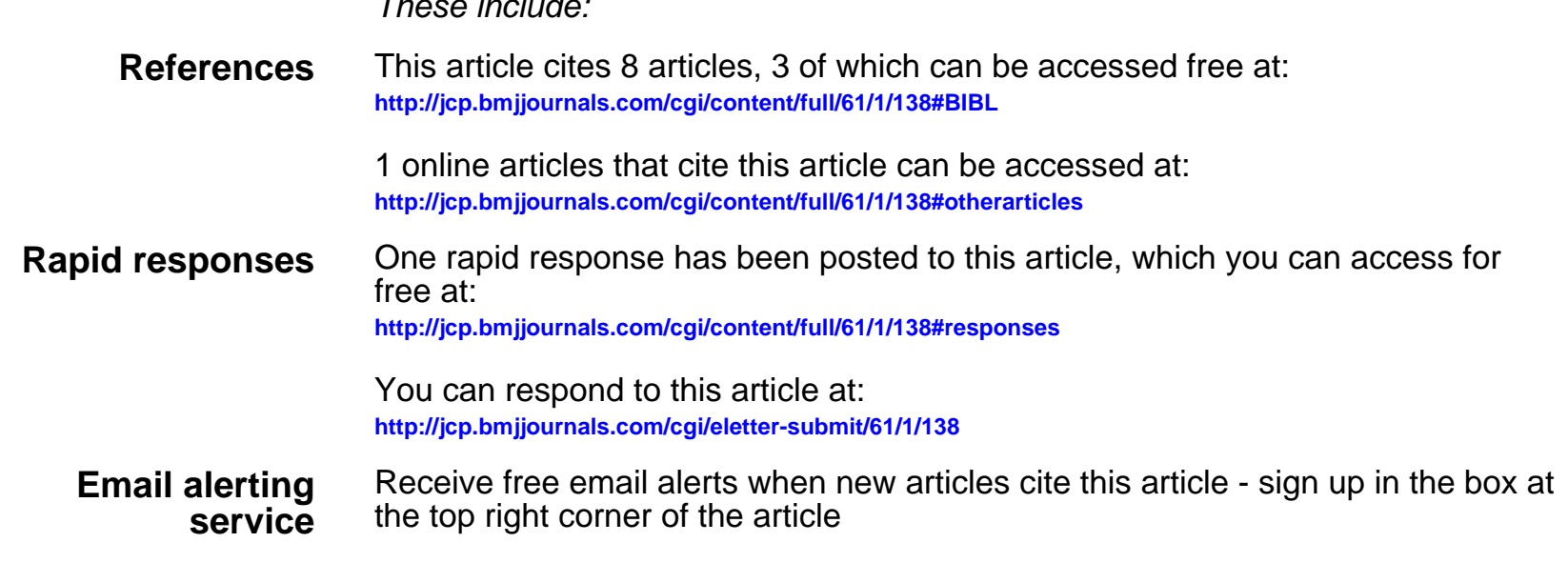

These include:

Notes

To order reprints of this article go to:

http://journals.bmj.com/cgi/reprintform

To subscribe to Journal of Clinical Pathology go to:

http://journals.bmj.com/subscriptions/ 


\title{
Salmonella typhimurium meningitis in an adult patient with AIDS
}

\author{
K Swe Swe, ${ }^{1}$ G Nagel, ${ }^{2} \mathrm{M}$ Van der Westhuizen, ${ }^{2}$ A A Hoosen ${ }^{1}$
}

${ }^{1}$ Department of Microbiological Pathology, Medunsa Campus, University of Limpopo, and the National Health Laboratory Services, Pretoria, South Africa; ${ }^{2}$ Department of Internal Medicine, Kalafong Hospital, Pretoria, South Africa

Correspondence to:

Dr Khine Swe Swe, Department of Microbiological Pathology,

Medunsa Campus, University of Limpopo, P0 Box 211, Medunsa, 0204, Pretoria, South Africa; Ksweswe2003@yahoo.com

Accepted 10 November 2006 Published Online First

8 December 2006

\section{ABSTRACT}

Salmonella meningitis is an unusual complication of Salmonella sepsis and occurs mainly in children. A rare case of Salmonella typhimurium meningitis occurring in an adult HIV positive man who presented with a history of fever and diarrhoea is reported. On examination he was dehydrated, and had oral thrush, weakness of lower limbs and neck stiffness. A septic diagnostic screen was performed and he was commenced on empiric intravenous cefotaxime therapy for meningitis. $S$ typhimurium was cultured from cerebrospinal fluid and blood culture specimens. It was non-lactose fermenting, oxidase negative, $\mathrm{H}_{2} \mathrm{~S}$ positive and motile. Cefotaxime was continued for 14 days and the patient responded without neurological sequelae.

We report a rare case of Salmonella typhimurium meningitis in a male patient in his 40s who was immunocompromised; he presented with fever, diarrhoea and neck stiffness to a regional hospital.

On examination, he was pale, dehydrated and confused, and had fever, oral thrush, weakness of lower limbs and neck stiffness. His temperature was $38.5^{\circ} \mathrm{C}$; blood pressure $88 / 40 \mathrm{~mm} \mathrm{Hg}$; pulse rate 120 beats/min and respiratory rate 28 breaths/ min. Specimens were collected for a septic screen which included a blood culture, cerebrospinal fluid (CSF) examination, as well as a full blood count, CD4 count and viral load. Stool and urine specimens were not collected. A clinical diagnosis of meningitis was made, and the patient was started on intravenous cefotaxime ( $3 \mathrm{~g}$ initial dose, followed by $2 \mathrm{~g}$ every 6 hours, ie $8 \mathrm{~g} /$ day).

A review of the patient's records indicated that he had been treated for pulmonary tuberculosis four months previously. There was no record of his HIV status or whether he had received antiretroviral treatment.

The laboratory results showed low haemoglobin $(97 \mathrm{~g} / \mathrm{l})$, normal white cell count $\left(9.4 \times 10^{\circ} / 1\right.$ with $89.1 \%$ neutrophils), high platelet count $\left(427 \times 10^{9} \%\right.$ 1); absolute CD4 count of $2 \times 10^{6} / 1$ and a viral load of 99658 RNA copies/ml (Nuclisens, BioMerieux, France). CSF analysis revealed a turbid appearance with polymorpho-neutrophils of $8965 / \mathrm{mm}^{3}$, red blood cells $495 / \mathrm{mm}^{3}$ and no lymphocytes. Total protein was raised at $2.98 \mathrm{~g} / \mathrm{l}$; there was low glucose $(0.3 \mathrm{mmol} / \mathrm{l})$ and low chloride (103 mmol/l). CSF and blood cultures yielded a pure growth of a Gram-negative bacillus which was identified as Salmonella sp by the Api $20 \mathrm{E}$ (BioMerieux) and agglutinated with serogroup B (Wellcolex, Remel, UK). It was identified as $S$ typhimurium by serotyping at the National Institute of Communicable Diseases, South Africa. It did not ferment lactose or sucrose, but fermented glucose. It was motile, oxidase negative, $\mathrm{H}_{2} \mathrm{~S}$ positive and ornithine reaction positive. ${ }^{1}$ Microbiological evidence suggested infection with Salmonella group B, serotype $S$ typhimurium meningitis and septicaemia.

Disc diffusion susceptibility testing (Kirby Bauer) showed the isolate to be susceptible to cefuroxime, cefotaxime, ceftriaxone, ciprofloxacin, and chloramphenicol, but resistant to ampicillin and cotrimoxazole. The patient was treated for 14 days with cefotaxime ( $3 \mathrm{~g}$ initial dose, followed by 2 g every 6 hours, ie $8 \mathrm{~g} /$ day) during which time he became apyrexial, well orientated and ready to be discharged for continued care at a hospice.

Non-typhoidal salmonella (NTS) infections are frequently associated with animal reservoirs and originate from ingestion of contaminated food products or water. ${ }^{1}$

$S$ typhimurium is usually associated with selflimiting gastroenteritis in immunocompetent persons. The mean duration of carriage of NTS in the stool is $4-5$ weeks and varies by Salmonella serotype; almost all chronic carriers are adults. ${ }^{1}$ The organism can spread to the bloodstream and rarely to the meninges in immunocompromised persons. In the case report by Ellis et al, the patient was elderly and diabetic, predisposing to the infection. ${ }^{2}$

HIV infected persons have a 20-100-fold increase risk of salmonellosis, including fulminant diarrhoea, acute enterocolitis, rectal ulceration, recurrent bacteraemia, meningitis, and death, despite appropriate antimicrobial therapy, compared to immunocompetent persons. Focal infections are infrequent among HIV-infected persons, most occurring among those with CD4 counts of $<100 / \mathrm{mm}^{3}{ }^{1}$

Central nervous system (CNS) infections occur in approximately $0.1-0.9 \%$ of NTS cases. ${ }^{3}$ Salmonella meningitis is rare in an adult patient, even in tropical areas where salmonellosis is common. ${ }^{4}$ The three serotypes most commonly associated with meningitis include $S$ enteritidis, $S$ paratyphi B and $S$ typhimurium, with the latter commonly occurring in children $<1$ year of age. ${ }^{5}$

With regard to meningitis in adults, 17 cases of NTS have been reported. Seven of these have been in HIV positive persons, but none had infection due to $S$ typhimurium. ${ }^{6}$ In the remaining 10 cases in which the HIV status was unknown, two were associated with $S$ typhimurium. ${ }^{8}{ }^{9}$ In these two cases the underlying problem was a traumatic fracture of first lumber vertebrae and postoperative wound infection for removal of a cerebral meningioma. These were associated with direct transmission of the organisms. The food source of the organism 


\section{Take-home messages}

- A rare complication of Salmonella typhimurium meningitis in an HIV positive adult patient is reported.

- The patient responded to treatment with intravenous cefotaxime.

was not found in our patient. However, we believe this is a gastrointestinal infection with subsequent spread to the CSF. Standard infection control measures were followed while the patient was hospitalised.

We have presented an unusual case of meningitis in an immunocompromised adult who had a CD4 count of $2 \times 10^{6} / 1$ and presented with diarrhoea. The patient, despite poor immune status, responded to appropriate antimicrobial therapy and was discharged without any neurological complication.
Competing interests: None declared.

\section{REFERENCES}

1. Pegues DA, Ohl ME, Miller SI. Salmonella species, including Salmonella typhi. In: Mandell GL, Bennett JE, Dolin R, eds. Principles and practice of infectious diseases, 6th edn. Philadelphia: Elsevier, 2005:2636-50.

2. Ellis ME, Smith CC, Reid TM, et al. Chloramphenicol-resistant Salmonella typhimurium meningitis in an adult. BMJ 1981:283:273.

3. Drevets DA, Leenen PM, Greenfield RA. Invasion of the central nervous system by intracellular bacteria. Clin Microbiol Rev 2004;17:323-47.

4. KoKo J, Dufillot D, Kani F, et al. Salmonella meningitis in children in Libreville, Gabon. A retrospective study of nine cases. Arch Pediatr 1997;4:1175-81.

5. Lee WS, Puthucheary SD, Parasakthi N. Extra-intestinal non-typhoidal Salmonella infections in children. Ann Trop Paediatr 2000;20:125-9.

6. Leonard MK, Murrow JR, Jurado R, et al. Salmonella meningitis in adults infected with HIV: case report and review of the literature. Am J Med Sci 2002;323:266-8.

7. Karim M, Islam N. Salmonella meningitis: reports of three cases in adults and literature review. Infection 2002;30:104-8.

8. Kauffman CA, St Hilaire RJ. Salmonella meningitis, occurrence in an adult. Arch Neurol 1979;36:578-80.

9. Singh RV, Yeh JS. Wound infection with meningitis caused by Salmonella typhimurium. Br J Neurosurg 1993;7:311-13.

\section{Stay a step ahead with Online First}

We publish all our original articles online before they appear in a print issue. This means that the latest clinical research papers go straight from acceptance to your browser, keeping you at the cutting edge of medicine. We update the site weekly so that it remains as topical as possible. Follow the Online First link on the home page and read the latest research. 